\title{
No Health Without Mental Health - European Clinical Psychology Takes Responsibility
} 1st European Congress on Clinical Psychology and Psychological Treatment in Dresden, Germany, October 31 November 2, 2019

Katja Beesdo-Baum ${ }^{\mathrm{a}}$, Tanja Endrass ${ }^{\mathrm{a}}$, Jürgen Hoyer ${ }^{\mathrm{a}}$, Corinna Jacobi ${ }^{\mathrm{a}}$, Philipp Kanske ${ }^{\mathrm{a}}$

[a] Institute of Clinical Psychology and Psychotherapy, Technische Universität Dresden, Dresden, Germany.

Clinical Psychology in Europe, 2019, Vol. 1(1), Article e34220, https://doi.org/10.32872/cpe.v1i1.34220

Published (VoR): 2019-03-29

Corresponding Author: Philipp Kanske, Institute of Clinical Psychology and Psychotherapy, Technische Universität Dresden, Chemnitzer Str. 46, 01187 Dresden, Phone +49 (0)351 463-42225, Fax +49 (0)351 463-36984. E-mail: philipp.kanske@tu-dresden.de

The European Association of Clinical Psychology and Psychological Treatment (EACLPT) was founded in 2017 with the goal of promoting European collaborations on research and education about mental health problems as well as their treatment. In 2019, the association's first congress will take place to foster such collaborations from October $31^{\text {st }}$ to November $2^{\text {nd }}$ in Dresden, Germany. It will be the first international meeting in the field of clinical psychology at a European level.

The conference theme "No Health without Mental Health - European Clinical Psychology Takes Responsibility" expresses our goal of moving mental health into societal focus. Mental disorders are among the most debilitating conditions and clinical psychology offers a wide range of preventive and therapeutic interventions. The discussion of these, as well as underlying etiological models, will be at the heart of the conference. Keynote speakers include Claudi Bockting, Susan Bögels (University of Amsterdam), David Clark (University of Oxford), Stefan Hofmann (Boston University) and Maria Karekla (University of Cyprus).

We invite submissions for symposia and poster presentations on the full range of clinical psychological research: diagnostics and classification, psychological and psychobiological mechanisms, psychological treatments, prevention and rehabilitation. We particularly encourage early career researchers to join the conference. Targeted pre-conference workshops, mentoring and financial support can be offered. 
The conference will be a unique chance to discuss current challenges for mental health in Europe and initiate collaborations and joint projects with colleagues from all over the continent. We look forward to seeing you in Dresden!

For details on the conference and registration visit:

www.clinicalpsychologycongress2019.eu

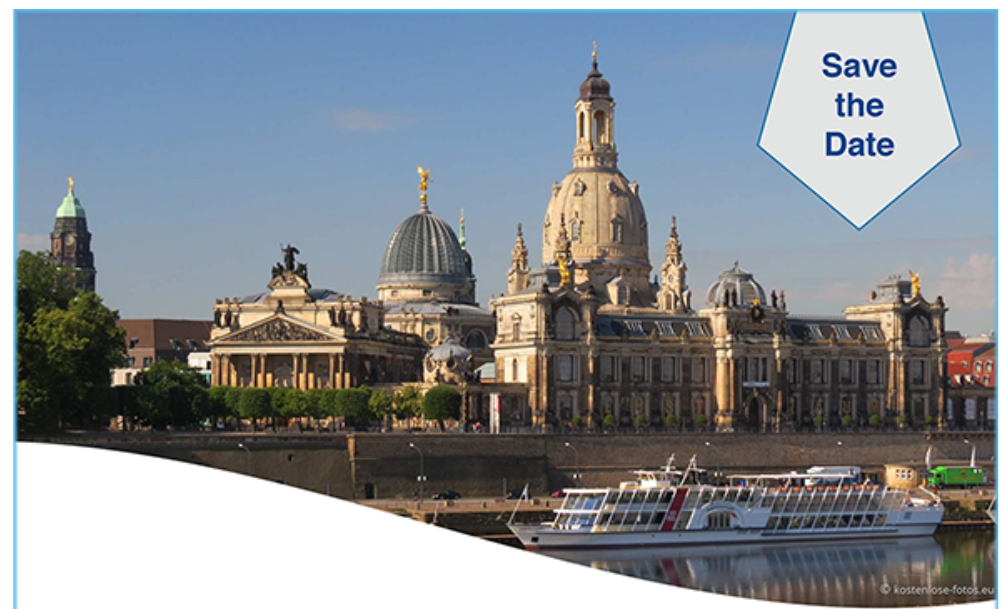

No Health without Mental Health:

European Clinical Psychology takes Responsibility

First official European Congress on Clinical Psychology and Psychological Treatment of EACLIPT

\section{Dresden, Germany \\ October 31 - November 2}

www.ClinicalPsychologyCongress2019.eu

TECHNISCHE
DNIVERSITAT $\begin{gathered}\begin{array}{c}\text { Institute of Clinical Psychology and Psychotherapy } \\ \text { Duropean Association of Clinical Psychology } \\ \text { and Psychological Treatment }\end{array} \\ \text { EACLIPT }\end{gathered}$

